\title{
¿Ha sido importante la cooperación internacional para el desarrollo y el crecimiento económico? Una evidencia de datos panel para Nicaragua y Centroamérica
}

\author{
Caroll Siero*, Rony Rodríguez. y Sebastián Hernández **
}

\section{Recibido: octubre de 2015 / Aceptado: noviembre de 2015}

La cooperación internacional al desarrollo ha sido divulgada como una operación que se realiza con el objetivo de promover el desarrollo y crecimiento económico de los países. Sin embargo, la cooperación no solamente se basa en la idea del mejoramiento económico de los países sino también en las relaciones políticoeconómicas que los países tienen y en la forma en que éstos administran los recursos. Esto sugiere que el estudio de la cooperación debe abordar contextos, políticas e ideales tanto de los cooperantes como de los beneficiarios. En el presente artículo se desarrollaron dos modelos econométricos, estimados a través de datos panel. Primero, un modelo de selectividad que hace referencia a la cantidad de dinero desembolsado a sectores estratégicos de la economía por parte de los donantes y, segundo, un modelo de eficacia de la cooperación para valorar la incidencia de la ayuda en el desarrollo y crecimiento económico. A través de estos dos modelos, el paradigma actual de la cooperación presenta debilidades al momento de establecer ejes estratégicos. Por esto, es necesario que el debate sobre el rol de la cooperación tenga un carácter activo en las políticas tanto de los países cooperantes como de los beneficiarios. JEL: F350, O10, O20. O470.

Palabras clave: cooperación internacional al desarrollo, desarrollo y crecimiento económico, datos panel, Nicaragua

Facultad de Ciencias Económicas y Empresariales de la Universidad Centroamericana, Managua. Correo electrónico: caroll.siero@ns.uca.edu.ni

** C-entro de Análisis SocioCultural y Grupo de Estudios Econométricos de la Facultad de Ciencias Económicas y Empresariales. Universidad Centroamericana, Managua. Correo electrónico: maximiliano.rod.ra@gmail.com

*** Grupo de Estudios Econométricos de la Facultad de Ciencias Económicas y Empresariales, Universidad Centroamericana. Correo electrónico: andres.nicol.hl@gmail.com 


\section{Introducción}

La cooperación internacional para el desarrollo (CID) ha sido un tema que, en cierta medida, se ha pasado por alto a la hora de analizar los problemas de desarrollo de los países. No solamente por el rol que juegan los países externos en las políticas dentro de los países receptores de cooperación, sino también en la forma de vincular iniciativas con el fin de saldar brechas sociales (educación, salud, entre otros), que han persistido durante los años. Según Burke (2008), la cooperación debería tener como objetivo contribuir a la reducción de la pobreza y al aumento de la sostenibilidad económica de los países, pero la existencia de agendas no coordinadas de los cooperantes ha provocado que la cooperación sea un obstáculo para reducir la pobreza. En este sentido, las políticas de ayuda externa han desembocado en la persistencia de una idea fraccionaria que se vincula al rol de cada actor dentro del desarrollo. Por ello existe la necesidad de analizar comparativamente la CID y, a su vez, cómo esta se ha venido incorporando en una agenda común a través ideas como la eficacia de la cooperación y su papel como un Objetivo del Milenio (ODM).

Según Sanahuja (2001) la CID también tiene una característica geoestratégica debido a que se comienza a hablar de cooperación luego de la Segunda Guerra Mundial y en el periodo tenso de la Guerra Fría. A partir de la caída del muro de Berlín, el proceso de globalización facilitó modificaciones sustanciales en las condiciones de los accesos al capital de inversiones de los países; así como la mayor presencia de la Inversión Extranjera Directa (IED) dentro de las cuentas nacionales de los Estados. Es por esto que Sanahuja (2001) plantea que estos procesos de globalización influyen en la capacidad de los Estados-Nación debido a que ponen en cuestión la soberanía nacional y las políticas exteriores de los países. Debido a la creciente presión de la globalización se ha proporcionado el establecimiento de nuevos paradigmas de cooperación, como la cooperación descentralizada, que buscan articular de manera eficiente los recursos para lograr un desarrollo más integral de la población.

Este es un dilema que se ha mostrado en los últimos años. Por un lado, existe la noción de que la CID tiene que empoderar a los beneficiados en busca de crear un vínculo fuerte entre población que recibe la donación y sus donantes. A su vez, esto ha sido descrito en los distintos Foros de Alto Nivel para la Eficacia de la Cooperación ${ }^{1}$.Sin embargo, el enfoque de cooperación descentralizada puede finalizar en procesos de asistencialismo,falta de capacidades especializadas en las estructuras administrativas, y en el incumplimiento de los acuerdos de la agenda de la eficacia de la ayuda (Pérez, 2011). Estos retos que se adentran en la dinámica de los países desarrollados y los países en vías de desarrollo son establecidos a partir del concepto de desarrollo que cada actor tiene; por lo cual, la preocupación por el desarrollo realmente trasciende a la agenda de los gobiernos y de organismos multilaterales perpetrando la percepción local en respuesta a las brechas sociales que existen en la población (Gutiérrez-Goiria, Villena \& Malagón, 2012).

1 El primer Foro de Alto Nivel sobre la Eficacia de la Ayuda fue el de Roma, Italia (2003), seguido de Paris, Francia (2005), Accra, Ghana (2008) y el último en Busan, Corea del Sur (2011). 
Al situarnos en un panorama de divergencias teóricas en torno al rol de los actores sobre la conceptualización del desarrollo, la idea de un estilo viable del desarrollo en términos de cooperación puede resultar muy poco atractivo e incluso puede llevar a confrontaciones de carácter ideológico. Es decir, existirán ambientes que no propiciarán un buen desenvolvimiento de los nuevos paradigmas de cooperación. Por lo cual, resulta necesario definir qué tipo desarrollo se busca alcanzar dentro de la sociedad. Siguiendo a Sen (2000) el desarrollo será conceptualizado como "un proceso de expansión de las libertades reales de que disfrutan los individuos" (p. 19).Esto sugiere la eliminación de aquellos procesos que privan de libertad a los individuos, como son la pobreza, la falta de oportunidades, represión, entre otros (Sen, 2000). Sin embargo, este concepto de desarrollo tomo un sentido más práctico dentro de la gestión política del desarrollo internacional. El concepto de "Desarrollo Humano" que adopto las Naciones Unidas entendió lo dicho por Sen como una simultaneidad entre lo económico y lo social, que al momento de medirse involucraba el uso de los indicadores que hoy conocemos forman parte del Índice de Desarrollo Humano como Esperanza de Vida al nacer, Tasa de Alfabetización, Nivel de Escolaridad y cierto énfasis en la capacidad de compra y nivel de vida en términos económicos que presenten los ciudadanos de un país -Crecimiento del PIB per cápita. Recientemente se ha incorporado la dimensión de género y, junto con los otros indicadores, este es un enfoque algo más completo como para regir como una de las metas base de la cooperación.

Por otro lado, según Wolfe (1976, citado en March, 2003) existen procesos de inviabilidad sociopolítica que se centran en los aspectos que impiden mantener la voluntad política en un conjunto determinado de objetivos de desarrollo. Según el video de AdecCba (2012), sobre un panel de discusión en torno a la CID, Martín Santiago sitúa al desarrollo como un cambio estructural de nuestros tiempos (del Siglo XXI) que es propicio por la cooperación en virtud de la propuesta del desarrollo local sostenido. De igual forma, el multilateralismo se emplea como una nueva forma de gobernabilidad para lograr administrar de mejor manera las agendas de desarrollo. Es decir, la agenda tiene que ser una agenda realmente para el desarrollo, asumiendo que el desarrollo tiene que ser dirigido hacia los individuos en las sociedades.

Al definir cuál debe ser la forma de gestionar el desarrollo y el rol que cada actor involucrado tiene o debe tener,se deben expresar de manera más explícita los problemas que los países tienen. Esto con la idea de alcanzar sociedades justas, así como la sostenibilidad donde los vínculos están estrictamente unidos y de forma coordinada. Aquí es donde el papel del Estado, los organismos multilaterales y la sociedad civil rigen un encadenamiento que debe facilitar los procesos y no ser obstáculos del desarrollo. Es por esta (des)vinculación que muchas veces dentro de los proyectos de ayuda al desarrollo se ignoran las condiciones de cada país por lo que las llamadas soluciones pre-fabricadas no son puestas en práctica de una manera idónea (Burke, 2008). LaCID, en términos de la eficacia de la ayuda al desarrollo, ha carecido de componentes estratégicos. Es decir, no se ha logrado ser congruente entre el discurso del desarrollo y la práctica, puesto que el vínculo que une a estos dos tipos de países (beneficiados y beneficiarios) no es más que un acuerdo insostenible que desvirtúa el concepto de desarrollo. 
Concordando con Pérez (2011), los momentos de crisis que han presentado los países desarrollados, y en especial los países europeos, pueden propiciar escenarios de reforzamiento en la estrategia de la eficacia de la ayuda (como caso de la crisis financiera del año 2008). Por lo que se deben crear escenarios donde sea más fácil detectar aquellos gastos que no han podido ser sostenibles y no han logrado crear un mejoramiento en el bienestar de la población beneficiada. Evitando la asimetría de los intereses y las distorsiones que se generan a partir de una agenda mal coordinada, la CID puede ser fruto de un sistema que limita la construcción al desarrollo, pero puede solidificar y (re) estructurar un plan más cercano a la transformación social de cambio que tenga como fin lograr mejorar las condiciones de vida de los ciudadanos en los países menos favorecidos. Así, el objetivo de este estudio fue analizar y discutir el esquema de cooperación que se ha presentado en la región centroamericana, y específicamente en Nicaragua; además de contrastar si los objetivos de la cooperación se están alcanzando teniendo presente compromisos internacionales, pero con dificultades en la praxis de la gestión de la ayuda.

Este documento se divide de la siguiente forma: en la sección 2 se presentan los argumentos teóricos tanto a favor como en contra al rol de la cooperación. En la sección 3 se explica la situación de la cooperación enfocándose en el rol de los donantes y se desarrolla el modelo de selectividad. En la sección 4 se discute el rol de los beneficiarios de la cooperación y, a su vez,se presentan los resultados del análisis econométrico sobre la eficacia de la ayuda. Por último, en la sección 5 se exponen las consideraciones finales sobre el rol de la cooperación en el desarrollo y crecimiento económico.

\section{El debate sobre el rol de la cooperación}

La literatura sobre la CID ha tenido dos ejes centrales: (1) los autores que están a favor de la ayuda como factor importante en el desarrollo de los países y (2) los autores que se oponen a esta idea. El debate en torno a la cooperación data de los años posteriores a la Segunda Guerra Mundial a través del rol que tuvo Estados Unidos en el desembolso de dinero para reconstruir Europa a través del Plan Marshall, oficialmente llamado European Recovery Program (Sogge, 2002). Paralelamente, se situó la discusión sobre la importancia de esta ayuda y sobre a qué sectores económicos iba a dirigirse este tipo de ayuda. Esto tuvo repercusión dentro de los economistas de la época y estimuló un debate enriquecedor con el objetivo de entender el funcionamiento de la ayuda para los países.

Los principales economistas que tuvieron una posición en contra sobre la ayuda como estimulando al crecimiento y desarrollo de los países fueron Friedman (1958) y Bauer (1972). Los dos llamaban a una baja de la ayuda y, a su vez, argumentaban que ésta no era un requerimiento para el crecimiento económico pues se convertía en un obstáculo dentro del buen desenvolvimiento de economía de libre mercado. Los dos autores establecieron que la asistencia a los gobiernos era altamente peligrosa debido a que incrementa el poder de las élites de los gobiernos receptores. Esto conlleva a la corrupción y obstaculiza el crecimiento. La inversión en el sector privado también se vería afectada debido a que la ayuda, de manera principal, es dirigida hacia los 
gobiernos y esto crearía una disyuntiva entre la inversión por parte del sector público y el sector privado.

La ayuda internacional al desarrollo ha tenido un rol pesimista. Por un lado, Bauer (1991) continuaba manteniendo que la ayuda era mala para el desarrollo, debido a que incrementaba los recursos de los gobiernos receptores, su patronal y, además, la ayuda hace que el Estado tenga mayor poder en relación con el resto de la sociedad. Es decir, tendría un rol preponderante dentro de la economía, que podría servir como un limitante dentro de su funcionamiento. Esta posición tiene un sentido más político sobre la ayuda en la economía y no se centra tanto en la efectividad que puede tener. Tanto la ayuda como su funcionamiento no sólo dependen de un costo político sino también de la estructura administrativa, la cual gestiona este tipo de recurso.

Un trabajo que ha sido altamente citado es el de Boone (1994). Este autor examina el efecto de la ayuda en diversas variables macroeconómicas y en distintos indicadores de desarrollo. El estudio concluye que no hay relación positiva significativa en la entrada de la ayuda hacia la inversión y en el crecimiento de los países en desarrollo. Sin embargo, algunas críticas que se pueden establecer al estudio de Boone son las relacionadas a una simple regresión lineal entre ayuda y crecimiento, lo cual puede ignorar, por completo, factores que puedan tener efecto directo o indirecto en el crecimiento. Es decir, aquellas que no se pueden capturar dentro de un modelo econométrico pero pueden tener efecto en el crecimiento y desarrollo. No obstante, estas críticas no son del todo completas debido a que Boone (1994) utiliza un sinnúmero de variables e indicadores que están relacionados con el crecimiento y, a su vez, con la ayuda. Básicamente, el estudio realizado por Boone muestra que no existe efecto alguno en los indicadores comúnmente utilizados para justificar los programas de la ayuda internacional.

Por último, otros estudios que han sido contribución notable de la literatura sobre la anti-ayuda son los realizados por Easterly (1999, 2001). Estos estudios han tenido como principal conclusión que el dinero de la ayuda ha sido mal gastado y al final no ha podido tener un resultado efectivo dentro del crecimiento económico de un país. A través del modelo "Two Gap", Easterly (1999) identifica que existe una discrepancia o brecha entre el crecimiento previsto y el crecimiento actual de la economía. La mayoría de los países donde se comprobó este tipo de dinámica de la ayuda internacional para el desarrollo fueron países africanos.

Dentro de la literatura que se encuentra a favor de la ayuda internacional para el desarrollo, estudios como el de Papanek (1973) y Levy (1988) han demostrado que existe un impacto positivo en el crecimiento. El análisis establecido era que la ayuda incrementa el crecimiento de los países a través de un aumento en el ahorro y en la inversión financiera, añadiendo al capital social. Además, estos autores argumentan que la cooperación facilita el incremento de la productividad, especialmente en la salud y en la educación. Asimismo, consideran que la transferencia de conocimiento y tecnología de los países ricos a los países pobres tiene un efecto positivo. Al igual que la literatura anti-ayuda las dos posiciones se centraban en ver el efecto de la cooperación en el crecimiento económico como un indicador de carácter macroeconómico. 
Dentro de los países que han sido identificados como grandiosos receptores de ayuda se encuentran Corea del Sur, Taiwán, Indonesia, Uganda y Mozambique. Estos estudios (Papanek, 1973; Levy 1988) toman en cuenta estos países, pero al igual que la literatura anterior estudiada, no incorporan el proceso político histórico en el cual se situaron estos países. Por ejemplo, tanto Corea del Sur y Taiwán tuvieron una recepción bastante considerable de ayuda a través de Estados Unidos como un eslabón fuerte contra el comunismo asiático. Fueron un pilar esencial geoestratégico que tuvo lugar en los años post Segunda Guerra Mundial. Sin embargo, los efectos no se pueden obviar y cada uno de estos países tuvo un mejoramiento significativo en la lucha contra la pobreza y en los indicadores de salud y de educación. Este tipo de estudios necesita ser más prolongado y abarcar otros aspectos dentro de la estructura económica y social de los países, así como su rol administrativo sobre la eficacia de la ayuda al desarrollo.

\section{El rol de los donantes}

Los flujos de cooperación han sido bastante persistentes a nivel regional. La ilustración 1 refleja que existe cierta tendencia al alza de la disponibilidad de fondos para la política al desarrollo. Sin embargo, no es un secreto que estos fondos son bastante vulnerables a las vicisitudes del contexto internacional. Los esfuerzos de cooperación comenzaron a llegar a la región hasta finales de la década de los 60 . Desde entonces estos fondos se han mantenido creciendo, con bajas en los períodos de conflictos internos (guerra civil salvadoreña, guerra contra-revolucionaria a finales de los 80 en Nicaragua) y las crisis internacionales (en especial la reciente crisis de 2008). Para 2006, los fondos habían alcanzado su máximo histórico en 6,373 millones de dólares constantes.

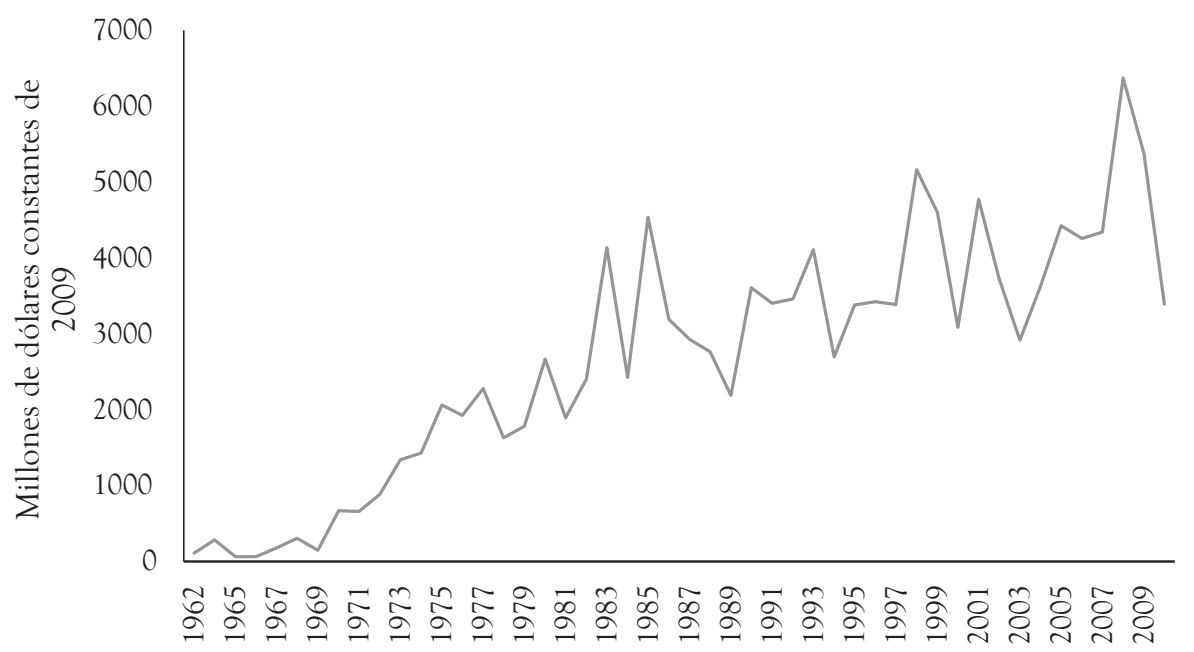

Ilustración 1. Cooperación oficial a Centroamérica

Fuente: Elaboración propia a partir de los datos AidData 2.1. 
En Nicaragua (ilustración 2) la discusión cobra otro sentido. La cooperación mantuvo su primer auge en las épocas previas y recientes a la Revolución Sandinista pero no se ve una mayor disponibilidad de fondos sino hasta el periodo de transición de los 90. Los fondos de esta época formaban parte de las estrategias de los organismos multilaterales en la instauración de un nuevo modelo económico y la época de ajuste estructural. No es sino hasta 2005 que existe una baja persistente en la CID. A partir de esta fecha pasan varios fenómenos, entre ellos, la revisión de 2006 de las estadísticas macroeconómicas de Nicaragua (Banco Central de Nicaragua, 2006) que sitúa al país en la categoría de país de renta media, categoría que no representaba una prioridad dentro de la política exterior de diversos cooperantes. Por otro lado, se ve una transición hacia una administración privada de los fondos de cooperación, dentro de las cuales destaca la presencia de Venezuela (ver cuadro 1). Así, los fondos de ayuda administrados oficialmente alcanzaron los 505.6 millones de dólares en 2013, mientras que los fondos privados, 790 millones de dólares.

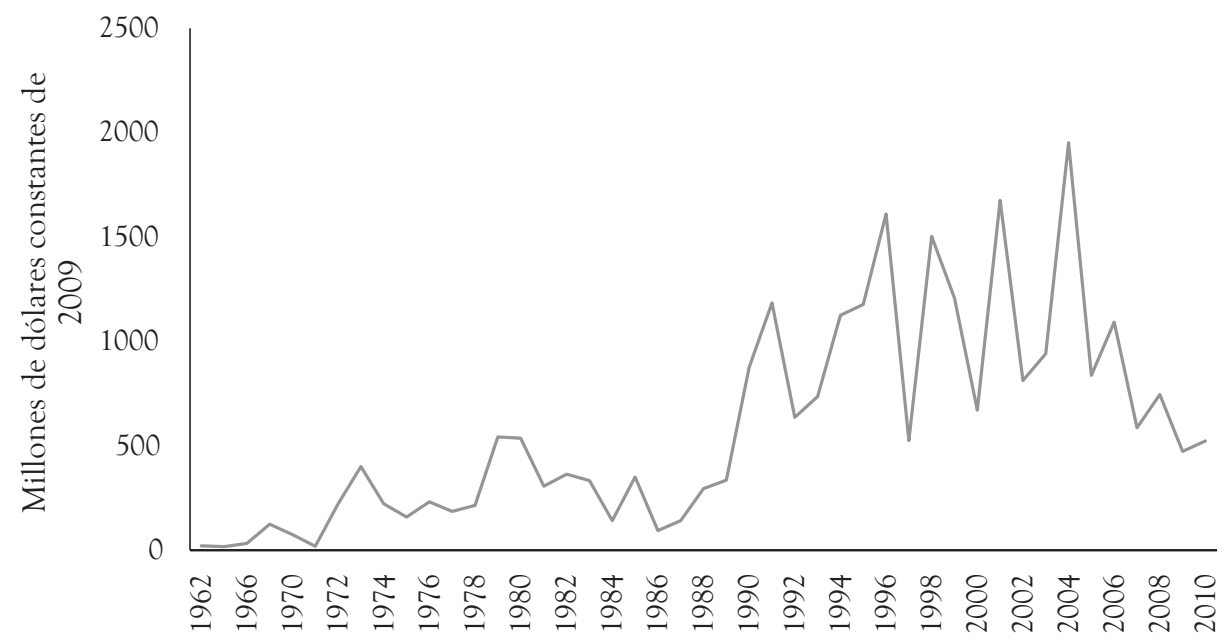

Ilustración 2. Cooperación oficial a Nicaragua

Fuente: Elaboración propia a partir de los datos AidData 2.1.

Ahora, si bien hay presencia de ciertos canales de cooperación, el impacto que ésta pueda tener en el desarrollo no es algo garantizado. Esto ha sido un tema de discusión incluido dentro de las agendas de la comunidad internacional. Representantes de los países donantes y los países en vías de desarrollo se han reunido numerosas veces en los llamados "Foros de Alto Nivel" (FAN). En los FAN se establecen compromisos explícitos tanto para donantes como receptores de la CID con el objetivo de mejorar la eficacia de la ayuda y asegurar la consecución de los objetivos o propósitos de los flujos de cooperación, ya sea reducción de pobreza, mejoramiento de las condiciones de vida o apoyo a los ODM. 
Cuadro1. Cooperación pública y privada de Nicaragua

\begin{tabular}{llllllll}
\hline & 2007 & 2008 & 2009 & 2010 & 2011 & 2012 & 2013 \\
\hline Pública & 653.1 & 528.5 & 605.2 & 518.3 & 493.1 & 484.9 & 505.6 \\
Privada & 123.6 & 364.3 & 293.9 & 589.7 & 684.2 & 631.9 & 575.7 \\
-Venezuela & 80 & 305.1 & 282.1 & 522 & 564.3 & 555.7 & 285.1 \\
\hline
\end{tabular}

Fuente: Elaboración propia a partir de los datos del Banco Central de Nicaragua.

Los FAN se han celebrado en cuatro ocasiones y dentro en cada uno se ha revisado las tendencias de la cooperación, el papel de los receptores y donantes dentro de la dinámica del desarrollo, y el enfoque de las estrategias de cooperación. Si bien cada FAN ha aportado nuevos elementos para el desenvolvimiento de un contexto más adecuado para donantes y receptores, se puede destacar como uno de los productos más emblemáticos a la declaración de Paris, elaborada en 2005 en el marco del segundo Foro de Alto Nivel. La Declaración de Paris reconoce la debilidad institucional y baja colaboración en las relaciones entre países socios y donantes (Organización para la Cooperación y el Desarrollo Económicos, 2009). De manera más concreta, dicha acta hace énfasis en los siguientes ejes temáticos sobre la ayuda:

- Apropiación: El que los países en vías de desarrollo establezcan sus propias prioridades.

- Alineamiento: Los donantes deben respetar las prioridades, planes y políticas de los países en desarrollo.

- Armonización: Los donantes coordinan flujos de cooperación en búsqueda de evitar la duplicación de esfuerzos y potenciar la especialización.

- Gestión Orientada a Resultados: Enfocan sus esfuerzos a resultados que puedan ser medidos y sujetos a evaluación.

- Responsabilidad Mutua: Tanto donantes como países de desarrollo se responsabilizan de la gestión e impacto de la ayuda frente a la población y las instituciones competentes.

Si bien se establecen compromisos para ambas partes, algunos países donantes no han adoptado a cabalidad medidas consecuentes con dichos ejes. Knack, Rogers y Eubank (2010) tratan de cuantificar la calidad de la ayuda y establecen un ranking de 38 donantes, tanto bilaterales como multilaterales, donde retoman aspectos claves de la Declaración de Paris. Si bien estos rankings no señalan que tanto los países donantes se han apropiado de los compromisos de segundo FAN, sirve de referencia para visualizar las buenas prácticas y el desempeño de las estrategias de los donantes en comparación con otros.

Este mismo análisis puede ser aterrizado a Centroamérica. La región guarda mucha homogeneidad respecto a quiénes son los proveedores de la ayuda. En el cuadro 2 se presentan los diez principales donantes de la última década para cada país de Centroamérica. Se logra evidenciar que en la región la cooperación está 
liderada por relaciones tanto bilaterales como multilaterales con los países de la Unión Europea y con acuerdos bilaterales con Estados Unidos, así la presencia del BID, los organismos adscritos al Banco Mundial y las Naciones Unidas y el acompañamiento del FMI es constante en la región.

Cuadro 2. Porcentaje de donantes entre los países (Promedio 2001-2011)

\begin{tabular}{lcllllllll}
\hline \multicolumn{2}{c}{ Costa Rica } & \multicolumn{2}{c}{ El Salvador } & \multicolumn{2}{c}{ Guatemala } & \multicolumn{2}{c}{ Honduras } & \multicolumn{2}{c}{ Nicaragua } \\
\hline & $\%$ & & $\%$ & & $\%$ & & $\%$ & & $\%$ \\
BID & 46.9 & BIRF & 23.1 & BIRF & 23.6 & EEUU & 17.3 & EEUU & 13.4 \\
BIRF & 18.0 & EEUU & 22.3 & España & 16.8 & Japón & 17.4 & España & 13.5 \\
ADC & 8.5 & BID & 21.5 & BID & 16.0 & BID & 14.4 & Alemania & 12.6 \\
FMI & 8.4 & España & 8.9 & EEUU & 11.8 & IDA & 12.6 & BID & 10.2 \\
Japón & 5.3 & FMI & 7.7 & FMI & 7.4 & España & 10.3 & IDA & 7.2 \\
Alemania & 3.1 & Alemania & 4.2 & Japón & 3.9 & Alemania & 6.4 & Japón & 6.6 \\
EEUU & 2.4 & EU & 3.3 & Holanda & 3.6 & UE & 5.2 & UE & 5.3 \\
Francia & 1.2 & Japón & 2.5 & UE & 2.8 & Canadá & 2.5 & Holanda & 4.6 \\
España & 1.2 & Luxemburgo & 1.4 & Suecia & 2.7 & Italia & 1.8 & Dinamarca & 3.5 \\
UE & 0.7 & FIDA & 0.7 & Alemania & 1.8 & Suecia & 1.7 & Suecia & 3.7 \\
\hline
\end{tabular}

Fuente: Elaboración propia a partir de los datos AidData 2.1

Claramente esto no excluye que existan ciertas particularidades en el manejo de los fondos de los cooperantes dentro de los países. Puede observarse que hay diferencias entre quienes tienen la mayor representatividad: el Banco Interamericano de Desarrollo para Costa Rica, el Banco Internacional de Reconstrucción y Fomento para El Salvador y Guatemala, Estados Unidos para Nicaragua y Honduras. De cualquier manera, la administración de los fondos de cooperación está fuertemente condicionada a las decisiones de las agencias a ayuda internacional.

Partiendo de esta premisa es posible evaluar cómo han adoptado estos donantes los acuerdo de los Foros de Alto Nivel. En el cuadro 3 se resumieron los resultados del estudio de Knack, Rogers y Eubank (2010). Para Centroamérica se visualiza que los donantes bilaterales se encuentran en posiciones bastantes bajas. En este sentido, países como Estados Unidos, España, Alemania y Francia se han visto más lentos al momento de adoptar los compromisos sobre la eficacia de la ayuda internacional. Sólo se ven en posiciones altas a los donantes multilaterales, cuyo aporte tiene mayor fuerza dentro de los flujos de ayuda de la región. 
Cuadro 3. Posición de los donantes sobre compromisos de los FAN

\begin{tabular}{|c|c|c|c|c|c|}
\hline & $\begin{array}{l}\text { \% de la CID } \\
\text { en C.A. }\end{array}$ & Alineamiento & Armonización & Especialización & Total \\
\hline \multicolumn{6}{|l|}{ Bilaterales } \\
\hline EEUU & 5.92 & 35 & 28 & 17 & 32 \\
\hline Japón & 4.08 & 8 & 35 & 24 & 27 \\
\hline España & 3.31 & 27 & 21 & 26 & 25 \\
\hline Alemania & 2.26 & 11 & 17 & 22 & 17 \\
\hline Francia & 0.78 & 15 & 27 & 12 & 24 \\
\hline Holanda & 0.54 & 6 & 8 & 18 & 6 \\
\hline Suecia & 0.52 & 13 & 20 & 13 & 11 \\
\hline Italia & 0.34 & 29 & 23 & 20 & 28 \\
\hline Canadá & 0.34 & 26 & 29 & 21 & 29 \\
\hline \multicolumn{6}{|c|}{ Multilaterales } \\
\hline FMI & 40.79 & 18 & 19 & 4 & 8 \\
\hline $\mathrm{BM}$ & 20.59 & 7 & 11 & 7 & 2 \\
\hline BID & 11.65 & 20 & 16 & 6 & 9 \\
\hline UE & 1.31 & 31 & 13 & 10 & 15 \\
\hline
\end{tabular}

Fuente: Knack, Rogers y Eubank (2010)

En este sentido, existen fuertes retos a resolverse entre aquellos que desembolsan el dinero para el desarrollo. Estados Unidos y España no ven buenos resultados en cuanto a la armonización de propósitos y la valoración de las prioridades nacionales. Para Alemania la situación amerita esfuerzos extra en la especialización. No se excluye que haya existido avances en estos cinco años que no cubre el estudio. Lamentablemente, no se pudo actualizar los datos por la falta de disponibilidad de insumos para su cálculo. Pero desde 1990 hasta 2011 esto representa un indicador fuerte sobre la eficacia de esos fondos.

\subsection{Modelo de selectividad de los donantes}

En la literatura empírica sobre la medición de la efectividad de la ayuda internacional, existe una especie de grupos de trabajos que plantean metodologías diferentes sobre los canales de transmisión, la dinámica de la cooperación y la metodología de medición. Según Winters y Martínez (2015) a través del análisis de composición de datos se puede crear un logaritmo de la cantidad de ayuda para cada país y que va a estar determinado de la ecuación (1):

$$
\log y=\alpha+\beta X_{d r}+\delta_{d}+\epsilon_{d r}
$$


Donde el logaritmo de la variable dependiente es el total de la cantidad de ayuda que los donantes dieron a los países. $\beta$ es un vector de coeficientes relacionados a variables teóricamente significativos dentro de la literatura sobre cooperación dentro de la que se incluyen características de los destinatarios y situación de las relaciones de estos últimos con los donantes; $\delta$ es un set de los efectos de los donantes, y por último, $\in$ es un error distribuido normalmente. Este modelo sirve para especificar los determinantes de la cantidad de los tipos de ayuda que se da entre los países.

En los cuadros $4 \mathrm{a}$ y $4 \mathrm{~b}$ se presentan los resultados correspondientes a la regresión lineal para la cooperación bilateral y multilateral, respectivamente. Estas regresiones se realizaron a partir de un panel de datos. Cada una de los cuadros, muestra los modelos que se realizaron incorporando las siguientes variables: WGI (Worlwild Governance Indicators) que es un índice agregado que captura valores de política y estabilidad, efectividad del gobierno, control de la corrupción, entre otros; Logaritmo PIB Per Cápita; Deuda, que representa el nivel de endeudamiento externo del país; Ratio de Inversión y Producto Interno Bruno; Logaritmo de Población, para incluir efectos por la cantidad de población; Logaritmo del Comercio entre los países y el donante; y Pobreza, como noción de robustez, para medir los cambios posibles en los coeficientes de las variables, así como su estabilidad dentro del modelo. Esta acotación se realizó tanto para el modelo de donantes bilaterales como para los donantes multilaterales.

Para el caso de los donantes bilaterales se estimó como variable dependiente las cantidades de ayuda que se desembolsó para los países de Centroamérica entre el año 2004-2010 por cada tipo de ayuda. Solamente los tipos de ayuda con referencia teórica se establecieron como variables dependientes. Es decir, aquel tipo de ayuda que se considera como relevante para el crecimiento y desarrollo de los países. Por un lado, para el total de ayuda, las variables que la determinan se encuentran el logaritmo del PIB per cápita, con valor negativo; y el logaritmo del comercio bilateral entre los países. Tanto para la cantidad de ayuda de tipo de infraestructura y social, no resultó ninguna variable significativa (con la excepción del comercio en el tipo de ayuda social).

Por otro lado, las variables con mayor significancia se encuentran en el modelo de tipo de ayuda a producción, sin incluir la variable pobreza dentro de su especificación. En cambio, cuando se incluye la variable pobreza dentro de los modelos, solo en el modelo de tipo de ayuda en infraestructura se encuentra la mayor parte de variables significativas; estableciendo que, el índice de gobernanza, la deuda del país, el comercio bilateral, y la pobreza son estadísticamente significativos dentro del modelo. Sin embargo, tanto para los modelos de tipo de ayuda de producción, social y el total de la ayuda, la única variable que resultó ser significativa fue el comercio bilateral entre los países. 
Cuadro 4a. Resultados de regresión lineal - Cooperante Bilateral

\begin{tabular}{|c|c|c|c|c|c|c|c|c|}
\hline \multirow[b]{2}{*}{ Variables } & \multicolumn{4}{|c|}{ Sin pobreza } & \multicolumn{4}{|c|}{ Con pobreza } \\
\hline & Total & $\begin{array}{l}\text { Infraes- } \\
\text { tructura }\end{array}$ & Social & $\begin{array}{l}\text { Produc- } \\
\text { ción }\end{array}$ & Total & $\begin{array}{l}\text { Infraes- } \\
\text { tructura }\end{array}$ & Social & $\begin{array}{l}\text { Produc- } \\
\text { ción }\end{array}$ \\
\hline \multirow[t]{2}{*}{ WGI } & 4.64 & -4.62 & -4.1 & $7.26^{* *}$ & -2.09 & $-43.76^{* *}$ & -0.7 & -5.88 \\
\hline & $(-3.17)$ & $(-6.41)$ & $(-6.39)$ & $(-3.35)$ & $(-7.14)$ & $(-16.79)$ & $(-13.02)$ & $(-21.94)$ \\
\hline \multirow{2}{*}{$\begin{array}{l}\text { Log(PIB } \\
\text { Per Cápita) }\end{array}$} & $-4.75^{\star}$ & 1.66 & 1.33 & $-6.97^{* *}$ & 0.42 & -5.11 & 1.48 & 3.36 \\
\hline & $(-2.47)$ & $(-5.45$ & $(-4.87)$ & $(-2.9)$ & $(-3.97)$ & $(-9.17)$ & $(-4.85)$ & $(-12.84)$ \\
\hline \multirow[t]{2}{*}{ Deuda } & $0.04^{* * *}$ & 0.01 & 0.02 & $0.04^{* * *}$ & 0.03 & $-0.26^{* * *}$ & 0.05 & 0.03 \\
\hline & $(-0.01)$ & $(-0.02)$ & $(-0.02)$ & $(-0.01)$ & $(-0.02)$ & $(-0.06)$ & $(-0.07)$ & $(-0.07)$ \\
\hline \multirow{2}{*}{$\begin{array}{l}\text { Inversión/ } \\
\text { PIB }\end{array}$} & 0.07 & -0.31 & -0.3 & $0.29^{*}$ & -0.27 & 0.44 & -0.34 & -0.41 \\
\hline & $(-0.16)$ & $(-0.4)$ & $(-0.34)$ & $(-0.15)$ & $(-0.26)$ & $(-0.64)$ & $(-0.3)$ & $(-0.78)$ \\
\hline \multirow[t]{2}{*}{ Log(Población) } & 2.79 & -3.95 & -3.07 & $5.78^{* * *}$ & -1.97 & -3.85 & -2.68 & -4.38 \\
\hline & $(-2.34)$ & $(-4.86)$ & $(-4.92)$ & $(-2.07)$ & $(-3.99)$ & $(-9.21)$ & $(-5.28)$ & $(-12.24)$ \\
\hline \multirow[t]{2}{*}{ Log(Comercio) } & $0.39^{* * *}$ & 0.53 & $0.38^{*}$ & $0.46^{*}$ & $0.47^{* * *}$ & $1.17^{* *}$ & $0.35^{*}$ & $0.61^{* *}$ \\
\hline & $(-0.11)$ & $(-0.48)$ & $(-0.21)$ & $(-0.24)$ & $(-0.14)$ & $(-0.49)$ & $(-0.2)$ & $(-0.24)$ \\
\hline \multirow[t]{2}{*}{ Pobreza } & & & & & -0.07 & $-25.41^{* * *}$ & 1.92 & 0.24 \\
\hline & & & & & $(-1.82)$ & $(-5.1)$ & $(-5.03)$ & $(-4.76)$ \\
\hline \multirow[t]{2}{*}{ Constante } & 1.76 & 65.1 & 56.01 & $-39.69^{*}$ & 45.86 & 138.24 & 46.02 & 58.82 \\
\hline & $(-24.39)$ & $(-48.82)$ & $(-51.42)$ & $(-23.17)$ & $(-42.1)$ & -96.49 & -61.49 & -121.65 \\
\hline Obs. & 147 & 90 & 110 & 99 & 137 & 85 & 104 & 92 \\
\hline \multirow{2}{*}{$\begin{array}{l}\mathrm{R}^{2} \\
\text { \# Donantes }\end{array}$} & 0.51 & 0.17 & 0.48 & 0.28 & 0.55 & 0.38 & 0.51 & 0.39 \\
\hline & 30 & 24 & 28 & 27 & 29 & 23 & 26 & 24 \\
\hline
\end{tabular}

Errores estándares robustos en paréntesis

${ }^{* * *} \mathrm{p}<0.01,{ }^{* *} \mathrm{p}<0.05,{ }^{*} \mathrm{p}<0.1$

Fuente: Elaboración propia a partir de los datos de AidData 2.1.

Para el caso de las regresiones lineales con los donantes multilaterales se omitió la variable comercio debido a que no existe comercio entre los países y estos donantes a como se da con los bilaterales. Dentro de la especificación de los modelos para distintos tipos de ayuda como variable dependiente se encontró que solamente en dos momentos existen variables significativas; para el caso de la ayuda de tipo social y para el total de la ayuda. Las variables significativas fueron pobreza, para el total de ayuda, y la constante para la ayuda de tipo social. A partir de esto se puede inferir que el tipo de condiciones que presentan los países centroamericanos para el desembolso de la ayuda, no es significativo para el donante multilateral. No obstante, el caso de la pobreza existente es la única variable relevante según los datos 
presentados.

Cuadro 4b. Resultados de regresión lineal - Cooperante Multilateral

\begin{tabular}{|c|c|c|c|c|c|c|c|c|}
\hline \multirow[b]{2}{*}{ Variables } & \multicolumn{4}{|c|}{ Sin pobreza } & \multicolumn{4}{|c|}{ Con pobreza } \\
\hline & Total & $\begin{array}{l}\text { Infraes- } \\
\text { tructura }\end{array}$ & Social & $\begin{array}{l}\text { Produc- } \\
\text { ción }\end{array}$ & Total & $\begin{array}{l}\text { Infraes- } \\
\text { tructura }\end{array}$ & Social & $\begin{array}{l}\text { Produc- } \\
\text { ción }\end{array}$ \\
\hline \multirow[t]{2}{*}{ WGI } & -3.02 & -0.81 & -5.46 & 1.93 & -2.76 & 2.69 & -6.74 & 2.95 \\
\hline & $(-2.17)$ & $(-5.08)$ & $(-5.67)$ & $(-7.7)$ & $(-3.69)$ & $(-6.4)$ & $(-4.87)$ & $(-12.7)$ \\
\hline \multirow{2}{*}{$\begin{array}{l}\text { Log(PIB Per } \\
\text { Cápita) }\end{array}$} & 1.99 & -1.06 & 3.26 & -0.04 & 3.15 & -1.45 & 5.39 & -0.36 \\
\hline & $(-1.98)$ & $(-4.41)$ & $(-4.76)$ & $(-6.29)$ & $(-2.55)$ & $(-4.28)$ & $(-4.46)$ & $(-7.94)$ \\
\hline \multirow[t]{2}{*}{ Deuda } & 0 & -0.01 & 0 & 0.02 & 0.02 & 0.01 & 0.01 & 0.02 \\
\hline & $(-0.01)$ & $(-0.01)$ & $(-0.01)$ & $(-0.01)$ & $(-0.01)$ & $(-0.02)$ & $(-0.02)$ & $(-0.04)$ \\
\hline \multirow{2}{*}{$\begin{array}{l}\text { Inversión/ } \\
\text { PIB }\end{array}$} & -0.1 & 0.06 & -0.28 & 0.16 & -0.18 & 0.05 & -0.39 & 0.16 \\
\hline & $(-0.11)$ & $(-0.24)$ & $(-0.3)$ & $(-0.45)$ & $(-0.15)$ & $(-0.23)$ & $(-0.28)$ & $(-0.58)$ \\
\hline \multirow[t]{2}{*}{ Log(Población) } & -1.07 & -0.5 & -4.17 & 5.2 & -1.87 & 0.1 & -5.28 & 5.24 \\
\hline & $(-1.47)$ & $(-3.37)$ & $(-4.21)$ & $(-7.19)$ & $(-2.28)$ & $(-3.35)$ & $(-3.83)$ & $(-9.62)$ \\
\hline \multirow[t]{2}{*}{ Pobreza } & & & & & $0.94^{* *}$ & 1.58 & 0.55 & 0.44 \\
\hline & & & & & $(-0.45)$ & $(-1.59)$ & $(-0.85)$ & $(-1.68)$ \\
\hline \multirow[t]{2}{*}{ Constante } & 19.8 & 29.51 & 64.71 & -74.15 & 23.61 & 19.81 & $67.28^{*}$ & -73.14 \\
\hline & $(-16.26)$ & $(-26.99)$ & $(-41)$ & $(-82.8)$ & $(-24.3)$ & $(-29.17)$ & $(-36.15)$ & $(-122.14)$ \\
\hline Obs. & 93 & 35 & 47 & 29 & 77 & 34 & 42 & 25 \\
\hline $\mathrm{R}^{2}$ & 0.19 & 0.37 & 0.28 & 0.45 & 0.31 & 0.44 & 0.38 & 0.43 \\
\hline \# Donantes & 21 & 12 & 13 & 12 & 20 & 12 & 12 & 11 \\
\hline
\end{tabular}

Errores estándares robustos en paréntesis

${ }^{* * *} \mathrm{p}<0.01,{ }^{* *} \mathrm{p}<0.05,{ }^{*} \mathrm{p}<0.1$

Fuente: Elaboración propia a partir de los datos de AidData 2.1.

\section{El rol de los beneficiarios}

\subsection{Modelo de eficacia}

Posteriormente se realizó un modelo de datos panel para Centroamérica correspondiente a los años 1990 - 2011. La razón de la inclusión de los países de la región dentro de este estudio se debe a: (1) la región mantiene una identidad de bloque que en la práctica se traduce a modelos de gestión de la ayuda bastantes similares a como se mencionó anteriormente, (2) la incidencia historia de la década perdida de América Latina fue especialmente compleja para Centroamérica ya que la época de los 80 s, el contexto de guerra modifico considerablemente el contexto económico de la región y la dimensiones y propósitos de la ayuda. Esto se refiere a circunstancias que compartieron los países de la región, que recién salían de 
guerras civiles a principios de los 90s, donde las "medicinas" que se usaban dentro de sus procesos de transición - en especial por donantes multilaterales como el Banco Mundial y el Fondo Monetario Internacional- estaban basados en un "Neoliberalismo con política social" (Morales, 2010) que se vio representado en las Estrategias de Crecimiento Económico y Reducción de Pobreza y los Programas de Ajuste Estructural de respectivos organismos. Estos hechos pueden generar relevancia dentro de las estimaciones por lo cual se restringe el análisis a la época desdetransición hasta la actualidad.

El uso de datos panel bajo el contexto de regresiones de crecimiento, platean mecanismos empíricos para probar el efecto de la ayuda sobre el crecimiento del PIB per cápita. Se utilizó la base de datos abiertos para el desarrollointernacional, AidData 2.1, que presenta registros sobre los flujos de proyecto de la CID entre países donantes y socios.

El modelo es estimado con el espíritu de Burnside y Dollar (2000). Tal modelo estima dos ecuaciones de determinantes de la ayuda oficial al desarrollo y el crecimiento de la riqueza per cápita. El modelo se estimó por medio de regresiones de efectos fijos. Basado en esto se seleccionóla siguiente especificación base:

$$
G D P=\alpha+\beta A i d+\gamma(\text { Aid } * \text { Pais })+\theta X+\epsilon
$$

La variable dependiente corresponde a la tasa de crecimiento del Producto Interno Bruto per cápita. Esta variable estará determinada por tres componentes: (1) Aid que corresponde a la magnitud de los flujos de cooperación en relación a la economía; medida como el peso porcentual de la ayuda respecto al PIB en dólares base $2005^{2}$. Este indicador posee la ventaja de ser comparable entre países y dar señalamientos más fuertes sobre la incidencia de la cooperación dentro de un determinado país. Por otro lado, se pretende indagar en las diferencias de Nicaragua respecto a la región, por ello se utiliza una interacción de Aid con las observaciones correspondientes a Nicaragua; esto aislará las particularidades del país y permitirá cuantificar las diferencias respecto a la incidencia regional de la CID. Por último, se introducen un grupo de variables de control. Tanto como los flujos de cooperación como el rendimiento de la producción se encuentran correlacionados con ciertas características al interior de la economía. El modelo anterior presta bastantes indicios de ello, al señalar que existe una significativa motivación de los cooperantes en las políticas comerciales de sus destinatarios, así mismo factores como la estabilidad macroeconomía y diferencias en las dotaciones de factores productivos pueden sesgar el coeficiente de la cooperación y confundir los resultados, por ello estos controles limpiaran el efecto de otras factores económicos relevantes dentro del análisis, una lista de estos controles se presenta en el cuadro 5.

2 Dado a que las bases de datos utilizadas ocupan diferentes años base para la armonización de las estadísticas del PIB y la CID; se crea un factor de ajuste calculado a partir de la relación del deflactor 2005 del banco mundial y un deflactor calculado para 2009. ( $\left(\frac{\text { Def } 2005}{\text { Def } 2009}\right)$ 
A partir del modelo base se estimaron otras dos especificaciones:

1. Modelo de evaluación de la eficacia de la ayuda por propósito. Se seleccionan 4 propósitos que a grandes rasgos representan los motivos de la ayuda en los últimos años: Social, Infraestructura y Producción, Multisectorial y Apoyo institucional. Cada flujo de ayuda está en porcentajes del PIB. Aquellos flujos de mayor impacto permitirán otorgar insumos para análisis comparativo sobre el uso de la AOD.

2. Modelo de evaluación del sistema político y descentralización. Lessman y Markwartt (2010) retoman la misma metodología de Burnside y Dollar (2000) pero aplican un contexto de descentralización política; para ello incluyen una variable que captura el efecto de la descentralización política y efectúan una variable interactiva para evaluar la eficacia de la ayuda bajo dicha modalidad. Así, para evaluar el efecto de la política en cada país se efectuó una regresión con una interacción sobre la ayuda y los países de estudio. Además de eso se incluyóun variable proxy sobre el estado de la democracia en el país.

Cuadro 5. Resumen de las variables

\begin{tabular}{|c|c|c|c|}
\hline & Unidad & Justificación & Origen \\
\hline Inflación & $\log (1+\operatorname{In} f)$ & $\begin{array}{l}\text { Aproximación de la estabilidad } \\
\text { macroeconómica }\end{array}$ & WDI \\
\hline Coeficiente de Apertura & $\%$ PIB & $\begin{array}{l}\text { Control de las relaciones de } \\
\text { intercambio derivados de la } \\
\text { cooperación }\end{array}$ & WDI \\
\hline $\begin{array}{l}\text { Déficit en Cuenta } \\
\text { Corriente }\end{array}$ & $\%$ PIB & $\begin{array}{l}\text { Captura el efecto de la entrada } \\
\text { neta de divisas a la economía }\end{array}$ & WEO \\
\hline Crecimiento Poblacional & $\%$ & Factor productivo & WDI \\
\hline Tasa de Ahorro & $\%$ & $\begin{array}{l}\text { Control la disponibilidad de } \\
\text { fondos locales para inversión }\end{array}$ & PWT \\
\hline Ayuda Total al Desarrollo & $\%$ PIB & Variables de análisis & AidData 2.1 \\
\hline Ayuda Social & $\%$ PIB & Variables de análisis & AidData 2.1 \\
\hline Ayuda en Producción & $\%$ PIB & Variables de análisis & AidData 2.1 \\
\hline Ayuda Multisectorial & $\%$ PIB & Variables de análisis & AidData 2.1 \\
\hline Ayuda Institucional & $\%$ PIB & Variables de análisis & AidData 2.1 \\
\hline Índice de Democracia ${ }^{3}$ & Numérica & $\begin{array}{l}\text { Evaluación de la eficacia del } \\
\text { contexto y medios para gestión de } \\
\text { la ayuda }\end{array}$ & $\begin{array}{l}\text { Vanhanen } \\
(2000)\end{array}$ \\
\hline Elecciones Municipales & $\begin{array}{l}1=\text { Elecciones } \\
\text { Ejecutivas } \\
\text { Locales }\end{array}$ & $\begin{array}{l}\text { Evaluación de la eficacia del } \\
\text { contexto y medios para gestión de } \\
\text { la ayuda }\end{array}$ & $\begin{array}{l}\text { Beck, Clarke, } \\
\text { Groff, Keefer } \\
\text { \& Walsh }\end{array}$ \\
\hline
\end{tabular}

3 Basado en la basa de datos de Vanhagen (2000) sobre la poliarquía, el índice de democracia es construido a partir de datos sobre las elecciones históricas de cada país, teniendo como indicadores clave la participación y la competencia que se presen-taron en cada ciclo electoral. 
Tal modelo corre el riesgo de presenta simultaneidad. Burnside y Dollar (2000) argumentan la presencia de simultaneidad corregida por medio de método generalizado de momentos. Sin embargo, los estimadores del modelo no cambian considerablemente por lo que otros autores han interpretado cierta polémica sobre la necesidad de corregir por endogeneidad de los estimadores. Probar que existe endogeneidad en datos panel es bastante delicado, ya que estará en dependencia de la fuerza de los instrumentos para verificar la presencia de la misma ${ }^{4}$. En nuestro caso se realizó una estimación de mínimos cuadrado con variables instrumentales, para este caso se identificaron dos variables instrumentales que cumplían con el requisito de correlacionarse tanto como con la variable dependiente como con el represor endógeno. Estas variables son el Índice de Capital Humano, retomado de la Penn World Table; y el PIB per cápita en dólares del año anterior. Los resultados arrojaron que en base los dos instrumentos no hay presencia de simultaneidad, las pruebas con solo un instrumento arrojaban endogeneidad, pero esta se debía más a la poca fuerza de los instrumentos al incluirlos dentro de la regresión. Por su parte, dado el interés de este estudio, se prefiere dar prioridad al correcto manejo de los errores estándar de la regresión, así que de existir sesgo en los coeficientes no se confundirán las interpretaciones que arrojen los resultados. Así, solo se correrá el modelo en mínimos cuadrados ordinarios con las particularidades que se mencionaran a continuación.

Aparte de la simultaneidad, existen otros aspectos a considerar. En primera el efecto de factores fijas en el tiempo que representan características particulares de cada país sesgar los coeficientes. Haciendo una prueba de Hausman se identificó que existen diferencias sistemáticas en el uso de estimaciones de panel por efecto fijo respecto a efecto aleatorio. La prueba estadística rechazo la igualdad de los parámetros de dichas estimaciones a un nivel de confianza de 1\%. Así mismo, el ocupar países plantea diferentes niveles de análisis que pueden provocar homocedasticidad, la prueba de hipótesis de Wald se rechaza al 1\% del nivel confianza. También existe presencia de correlación contemporánea y auto correlación. Esto reduce la precisión de los errores estándar, para corregirlos se reestiman las regresiones por medio de estimaciones de mínimos cuadrados robustos dentro de grupos. Las pruebas estadísticas para el modelo basese presentan en el cuadro 6.

4 Para más información de pruebas estadísticas en datos panel véase Wooldridge (2002). 
Cuadro 6. Pruebas de Violación de Supuestos en Datos Panel

\begin{tabular}{|c|c|c|c|}
\hline Ho: & (1) & (2) & (3) \\
\hline $\begin{array}{c}\text { Efecto fijo (Hausman) } \\
\qquad \beta_{\mathrm{fe}}=\beta_{\mathrm{ae}}\end{array}$ & $17.86^{* *}$ & & \\
\hline $\begin{array}{l}\text { Endogeneidad (Sargan-Hansen) } \\
\text { No hay endogeneidad }\end{array}$ & 1.448 & & \\
\hline $\begin{array}{l}\text { Fuerza del Instrumentos (Cragg-Donald) } \\
\text { Instrumentos débiles }\end{array}$ & 0.935 & & \\
\hline $\begin{array}{l}\text { Homocedasticidad (Modificación de Wald) } \\
\text { Presencia de no heteroscedasticidad }\end{array}$ & $163.89^{* * *}$ & $158.81^{* * *}$ & $108.21^{* *}$ \\
\hline $\begin{array}{l}\text { Correlación serial (Drukker) } \\
\text { Independencia serial }\end{array}$ & $7.795^{*}$ & $7.819^{*}$ & $8.465^{*}$ \\
\hline $\begin{array}{l}\text { Correlación Contemporánea(Breusch-Pagan) } \\
\text { Independencia contemporánea }\end{array}$ & $42.44^{* *}$ & $46.619^{* *}$ & $57.411^{* * *}$ \\
\hline
\end{tabular}

Fuente: Elaboración propia a partir de los datos de AidData 2.1.

Los resultados de las regresiones de eficacia (ver cuadro 7) demuestran que la ayuda en la región no ha tenido cierta uniformidad dentro de su impacto. El coeficiente de la ayuda no es significativo a niveles de confianza esperados y los resultados no son robustos. En primera instancia, el modelo base sugiere que la ayuda internacional ha tenido un efecto ambiguo en el crecimiento de la región, es decir que en términos promedios no ha favorecido a que en los últimos 20 años los países sufran cierto despegue en el crecimiento.

Aparte, una mirada general de los controles de la regresión revela que la estimación es robusta entre las especificaciones del estudio. Tanto la apertura comercial como el déficit en cuenta corriente revelan la amplia inclinación de los países a sistemas de ayuda comercial más que ayuda al desarrollo. Estos resultados son consistentes con el esquema de "ayuda mutua" que se visualizaba en el apartado anterior. 
Cuadro 7. Modelo Eficacia de la ayuda

\begin{tabular}{|c|c|c|c|}
\hline & (1) & (2) & (3) \\
\hline \multirow[t]{2}{*}{ Inflación } & -2.3744 & -2.6555 & 0.4402 \\
\hline & 3.3808 & 3.1064 & 2.3508 \\
\hline \multirow[t]{2}{*}{ Coeficiente de Apertura } & 0.0335 & 0.0214 & $0.0296^{*}$ \\
\hline & 0.019 & 0.0136 & 0.0137 \\
\hline \multirow[t]{2}{*}{ Déficit en Cuenta Corriente } & $-0.2244^{* * *}$ & $-0.2223^{* * *}$ & $-0.2352^{* * *}$ \\
\hline & 0.0567 & 0.0524 & 0.0368 \\
\hline \multirow[t]{2}{*}{ Crecimiento Poblacional } & 0.5934 & 0.3904 & 1.1525 \\
\hline & 1.2157 & 1.1527 & 0.7281 \\
\hline \multirow[t]{2}{*}{ Tasa de Ahorro } & 0.1804 & 0.3188 & -0.208 \\
\hline & 0.4454 & 0.3998 & 0.3995 \\
\hline \multirow[t]{2}{*}{ Cooperación Internacional al Desarrollo } & -0.0315 & & 0.334045 \\
\hline & 0.1293 & & 0.276 \\
\hline \multirow[t]{2}{*}{ Nicaragua * CID } & $0.3768^{*}$ & & \\
\hline & 0.1406 & & \\
\hline \multirow{2}{*}{ Ayuda Social } & & 0.6034 & \\
\hline & & 0.3347 & \\
\hline \multirow[t]{2}{*}{ Ayuda en Producción } & & $0.3983^{*}$ & \\
\hline & & 0.198 & \\
\hline \multirow[t]{2}{*}{ Ayuda Multisectorial } & & -0.2636 & \\
\hline & & 0.8552 & \\
\hline \multirow[t]{2}{*}{ Ayuda Institucional } & & 0.1001 & \\
\hline & & 0.1804 & \\
\hline \multirow[t]{2}{*}{ Índice de Democracia } & & & $-0.1287^{* *}$ \\
\hline & & & 0.0413 \\
\hline \multirow[t]{2}{*}{ Elecciones Municipales } & & & $0.838^{* * *}$ \\
\hline & & & 1.9027 \\
\hline \multirow[t]{2}{*}{ Democracia* CID } & & & 0.1697 \\
\hline & & & 0.0129 \\
\hline \multirow[t]{2}{*}{ Elecciones Municipales * CID } & & & $-0.3479^{*}$ \\
\hline & & & 0.1732 \\
\hline Constante & -3.5308 & -2.7011 & $-7.5004^{* *}$ \\
\hline $\mathrm{N}$ & 148 & 148 & 143 \\
\hline R Cuadrado & 0.1155 & 0.1047 & 0.1958 \\
\hline
\end{tabular}

Fuente: Elaboración de propia a partir de los datos de AidData 2.1.

A nivel de país se observa que en Nicaragua el efecto de la ayuda es significativo y del signo esperado. El coeficiente de la integración muestra que el efecto de la ayuda en Nicaragua representa 0.31 puntos porcentuales de crecimiento del PIB per cápita en comparación con el efecto promedio de la CID al crecimiento de la región centroamericana. 
Las demás especificaciones revelan otros puntos clave. La descomposición de la ayuda revela que el tipo de ayuda de mayor incidencia es aquella destinada a la producción. De igual forma, los destinos de la ayuda han variado significativamente en estas dos décadas (ver cuadros A.1 y A.2 en anexos). Sin embargo, en el último quinquenio la ayuda de la región parece haberse concentrado más en el apoyo a mejorar la burocracia gubernamental y modificar la gobernanza de la región. Por otro lado, Nicaragua tiene considerablemente mayor cantidad de CID destinada a sectores productivos, en especial en la agricultura. Esto no sugiere que los demás rubros a los que se pueda destinar la cooperación sean esfuerzos en vano. Ciertamente y por si solos, cada uno de los rubros a los que se destine la CID pueden ofrecer resultados deseables, mas estos resultados no se traducen a un mayor rendimiento de la economía.

Finalmente, hay que considerar diversos aspectos sobre la institucionalidad. La democracia no sólo no es un medio para argumentar una mejor eficacia de la ayuda, sino que incluso no muestra resultados esperados en las regresiones de crecimiento. Esto no pretende ser un ataque a la consecución de la democracia; sin embargo, bajo perspectivas institucionalistas, esta es plenamente asociada con la capacidad productiva del país, ya que sugiere una mayor apropiación de las necesidades socio-productivas y una mejor distribución de recursos. Claramente, el concepto de democracia puede ser lo suficientemente intangible como para ser reducido al indicador que se usa, pero el argumento de una distribución más eficaz de los recursos en base a una fuerte base social no parece tener tanta fuerza si se está en un contexto de poco alineamiento por parte de los donantes de dichos fondos. La descentralización política muestra resultados positivos como medio gestor de la ayuda al desarrollo. Es fácil de evidenciar que una de las nuevas tendencias a la gestión de la CID es el manejo directo con gobiernos locales. En este sentido, las mejoras en la planificación de los gobiernos locales parecen tener un impacto positivo en el crecimiento, pero no representan una mejora en la administración de la cooperación. Probablemente esto está relacionado con si es esta forma de gestión involucra presión sobre aferrarse o no a los ejes de la planificación nacional, sin embargo, este estudio está fuera del alcance de corroborar tal aseveración.

\section{Consideraciones finales}

La CID es un tema que ha sido y sigue siendo de debate entre los economistas y hacedores de políticas. Por un lado, las corrientes de pensamiento económico siguen juzgando de manera positiva o negativa este tipo de instrumentos, desde el tipo de ayuda que se realiza hasta la forma en que se devuelve la misma. Para el caso de los países en Centroamérica sigue siendo algo de carácter esencial dentro de sus economías y, a su vez, dentro de sus políticas. La representatividad y homogeneidad de la ayuda oficial en estos países ha facilitado un diseño estructural del tipo de ayuda que reciben y de la forma en que se gastan. Sin embargo, las características que presentan los países de Centroamérica no representan un peso fuerte en el desembolso de la cooperación de los países o de las instituciones multilaterales. Para el caso de los donantes bilaterales, se posiciona con mayor relevancia el nivel 
de comercio que tienen con los receptores, lo cual sugiera que la ayuda tiene como objetivo fortalecer los vínculos comerciales. El tipo de ayuda al sector de producción es la más relevante para los donantes bilaterales. Esto indica que existe un interés más económico de la ayuda hacia la transformación de la economía de los países receptores. No obstante, cuando se incluye la variable pobreza dentro del modelo de selectividad de la ayuda, el tipo de ayuda que cobra relevancia es la destinada a infraestructura. Para el caso de los donantes multilaterales solo el nivel de pobreza de los países es representativo para el total de ayuda desembolsada. De igual forma las características estructurales como el PIB Per Cápita, la población, el índice WGI para retomar la buena gobernanza de los países, no generan mucha significancia en el monto desembolsado del tipo de ayuda en los países, ya sea por parte de los donantes bilaterales o multilaterales.

Por último, la CID no tiene mucha incidencia en la consecución de objetivos de crecimiento económico. El modelo de eficacia arroja que no existe una relación significativa entre el peso de la ayuda dentro de cada país de la región y las tasas de crecimiento que éstos registran. Esto no tiene que ser interpretado como un llamado a cesar toda fuente de ayuda; por el contrario, es una invitación a repensar las cosas. Los esfuerzos de las CID son esfuerzos deseables pero que no dejan de exigir nuevos compromisos, o al menos, buenas respecto a los viejos. En este caso, los compromisos se visualizan para ambas partes, para que así pueda haber una adecuada articulación de actores.

Lo anterior debe verse más como un esquema de verdadera responsabilidad conjunta donde se respeten las prioridades de la política interna y los espacios de soberanía. Contrario a esto, la práctica o la intuición de algunos donantes sugieren que los destinatarios tienenla responsabilidad de la poca eficacia de sus fondos, debido a la mala administración y a un inadecuado reconocimiento de las prioridades socio económicas. La evidencia que recoge esta estimación señala lo contrario. Si el objetivo último de lanación es destinar fondos para proporcionar ciertas medicinas institucionales y responsabilizar el contexto político como catalizador de la ayuda, se está por buen camino. Pero si el objetivo es un bienestar físico generalizado y/o el crecimiento económico, el paradigma actual no parece estar dando buenos resultados.

\section{Referencias bibliográficas}

AdecCba. (2012, 21 de diciembre). Panel: "La cooperación internacional para el desarrollo" [Archivo de video]. Recuperado de https://www.youtube.com/ watch?v= LvXYFmr1X7 k\&hd=1

Banco Central de Nicaragua. (2006). Sistema de Cuentas Nacionales de Nicaragua: Año de Referencia 2006. Managua: Autor.

Bauer, P. (1972). Dissent on Development. Cambridge: Harvard University Press.

Bauer, P. (1991). The Development Frontier: Essays in Applied Economics. London: Harvester Wheatsheaf.

Boone, P. (1994). The Impact of Foreign Aid on Savings and Growth [Center for Economic Performance - Working Paper No. 677]. London: London School 
of Economics.

Burke, M. (2008). Introducción. En A. Bendaña et al. (Autor). Modelos de cooperación internacional en Centroamérica: perspectivas de los movimientos sociales (pp. 13-26). Managua: Centro de Estudios Internacionales.

Burnside, C. \& Dollar, D. (2000). Aid, Policies, and Growth. The American Economic Review, 90(4), 847-868.

Easterly, W. (1999). The Ghost of Financing Gap: Testing the Growth Model Used in the International Financial Institutions. Journal of Development Economics 69(24), 423-238.

Easterly, W. (2001). The Elusive Quest for Growth: Economist Adventures and Misadventures in the Tropics. Cambridge: Massachusetts Institute of Technology Press.

Friedman, M. (1958). Foreign Economic Aid. Yale Review, 47(4), 501-516.

Gutiérrez-Goiria, J., Villena, U. \& Malagón, E. (2012). ¿Nuevas Prácticas o Réplica a otra Escala? La Cooperación Descentralizada y su Especificidad desde el Caso del País Vasco. Revista de Economía Crítica, (14), 37-62.

Knack, S., Rogers, F.\& Eubank, N. (2010).Aid Quality and Donor Rankings [Policy Research Working Paper 5290]. Washington: The World Bank.

Lessman, C. \& Markwartt, G. (2010). Decentralization and Foreign Aid Effectiveness: Do Aid Modality and Federal Design Matter in Poverty Alleviation? [CESifo Working Paper Series No. 3035]. Munich: CESifo.

Levy, V. (1988). Aid and Growth in Sub-Saharan Africa: The Recent Experience. Journal of Development Studies, 37(6), $42-65$.

March, J. (2003). Desarrollo, Excedente y Producción. Valencia: Universitat de València.

Morales, H. (2010). Cooperación Internacional en Centroamérica: Mirada Crítica desde los Sujetos Políticos Regionales. Guatemala: Colectivo CAD.

Organización para la Cooperación y el Desarrollo Económico. (2009). Declaración de París sobre la Eficacia de la Ayuda al Desarrollo y Programa de Acción de Accra. Recuperado de: http://www.oecd.org/dac/effectiveness/34580968.pdf

Papanek, G. (1973). Aid, Foreign Private Investment, Savings, and Growth in Less Developed Countries. Journal of PoliticalEconomy, 81(1), 120-130.

Pérez, A. (2011). Crisis y Debate en la Cooperación Descentralizada. Recuperado de http://www.realinstitutoelcano.org/wps/wcm/connect/df2fb28046fcbabeb 151bf00526b8882/ARI98-2011_Perez_Crisis-debate-+cooperacion_ descentralizada.pdf?MOD=AJPERES\&CACHEID=df2fb28046fcbabeb151b f00526b8882

Sanahuja, J. (2001). Del Interés Nacional a la Ciudadanía Global: La Ayuda al Desarrollo y las Trans-formaciones de la Sociedad Internacional. En M. Gómez \& J. Sanahuja (Coords.). La Cooperación del Desarrollo en un Mundo de Cambio: Perspectivas sobre Nuevos Ámbitos de Intervención (pp. 51-128). Madrid: CIDEAL.

Sen, A. (2000). Desarrollo y Libertad. Buenos Aires: Planeta.

Sogge, D. (2002). Give and Take: What's the Matter with Foreign Aid? London: Zed Books.

Vanhagen, T. (2000). A New Dataset for Measuring Democracy. Journal of Peace Research, 37(2), 251-265.

Winters, M. \& Martínez, G. (2015). The Role of Governance in Determining 
Foreign Aid Flow Composition. World Development, 66(1), 516-531.

Wooldridge, J. (2002). Econometric Analysis of Cross Section and Panel Data. Cambridge: The MIT Press.

\section{Anexos}

Cuadro A.1. Propósito de la ayuda: Centroamérica

\begin{tabular}{|c|c|c|c|c|c|}
\hline & 1990 & 1995 & 2000 & 2005 & 2010 \\
\hline Educación & $3.10 \%$ & $6.62 \%$ & $6.45 \%$ & $8.76 \%$ & $5.12 \%$ \\
\hline Salud & $0.98 \%$ & $4.22 \%$ & $2.48 \%$ & $4.09 \%$ & $4.14 \%$ \\
\hline Política Demográfica & $1.00 \%$ & $0.15 \%$ & $1.25 \%$ & $1.64 \%$ & $1.83 \%$ \\
\hline Agua Potable y Saneamiento & $2.22 \%$ & $6.41 \%$ & $4.28 \%$ & $1.53 \%$ & $11.02 \%$ \\
\hline Gobernabilidad y Sociedad Civil & $13.28 \%$ & $13.18 \%$ & $9.28 \%$ & $4.04 \%$ & $17.15 \%$ \\
\hline Otras Infraestructuras Sociales & $2.52 \%$ & $6.62 \%$ & $6.05 \%$ & $7.03 \%$ & $6.28 \%$ \\
\hline Transporte y Almacenamiento & $5.81 \%$ & $12.15 \%$ & $9.86 \%$ & $6.75 \%$ & $14.15 \%$ \\
\hline Comunicaciones & $1.66 \%$ & $0.07 \%$ & $0.59 \%$ & $0.16 \%$ & $0.09 \%$ \\
\hline Generación de Energía Eléctrica & $1.89 \%$ & $5.46 \%$ & $14.66 \%$ & $2.49 \%$ & $5.06 \%$ \\
\hline Banca y Servicios Financieros & $7.62 \%$ & $4.32 \%$ & $1.79 \%$ & $1.49 \%$ & $3.60 \%$ \\
\hline Servicios Empresariales & $0.01 \%$ & $1.37 \%$ & $1.55 \%$ & $1.23 \%$ & $0.70 \%$ \\
\hline Agricultura, Silvicultura y Pesca & $6.98 \%$ & $4.52 \%$ & $5.72 \%$ & $4.15 \%$ & $5.28 \%$ \\
\hline Industria, Minería y Construcción & $3.21 \%$ & $1.87 \%$ & $1.64 \%$ & $0.94 \%$ & $0.96 \%$ \\
\hline Política y Regulación Comercial & $0.01 \%$ & $0.41 \%$ & $0.06 \%$ & $1.36 \%$ & $0.46 \%$ \\
\hline Protección del Medio Ambiente & $0.24 \%$ & $2.30 \%$ & $3.45 \%$ & $2.47 \%$ & $3.50 \%$ \\
\hline Política de Género & $0.00 \%$ & $0.46 \%$ & $0.12 \%$ & $0.04 \%$ & $0.00 \%$ \\
\hline Ayuda Multisectorial & $4.26 \%$ & $2.04 \%$ & $2.10 \%$ & $17.58 \%$ & $1.54 \%$ \\
\hline Desarrollo Urbano & $2.13 \%$ & $0.05 \%$ & $0.86 \%$ & $0.52 \%$ & $0.38 \%$ \\
\hline Desarrollo Rural & $1.99 \%$ & $1.70 \%$ & $5.53 \%$ & $2.43 \%$ & $0.96 \%$ \\
\hline Otras Ayuda Multisectoriales & $0.01 \%$ & $0.11 \%$ & $0.14 \%$ & $0.15 \%$ & $0.29 \%$ \\
\hline Apoyo Presupuestario & $28.49 \%$ & $6.32 \%$ & $8.91 \%$ & $1.46 \%$ & $11.08 \%$ \\
\hline Seguridad Alimentaria & $5.66 \%$ & $0.87 \%$ & $2.91 \%$ & $2.08 \%$ & $1.33 \%$ \\
\hline Asistencia de Mercancías & $2.20 \%$ & $0.12 \%$ & $0.08 \%$ & $0.49 \%$ & $0.00 \%$ \\
\hline Deuda Externa & $1.05 \%$ & $16.94 \%$ & $4.35 \%$ & $23.83 \%$ & $0.03 \%$ \\
\hline Ayuda Humanitaria General & $0.00 \%$ & $0.00 \%$ & $0.00 \%$ & $0.01 \%$ & $0.02 \%$ \\
\hline Emergencia & $3.33 \%$ & $1.31 \%$ & $1.42 \%$ & $1.52 \%$ & $1.26 \%$ \\
\hline Alivio para Reconstrucción & $0.00 \%$ & $0.00 \%$ & $3.53 \%$ & $0.07 \%$ & $0.18 \%$ \\
\hline Mitigación de Desastres & $0.00 \%$ & $0.00 \%$ & $0.55 \%$ & $0.04 \%$ & $1.15 \%$ \\
\hline Costos Administrativos & $0.00 \%$ & $0.00 \%$ & $0.09 \%$ & $0.06 \%$ & $0.67 \%$ \\
\hline Apoyo a ONG & $0.00 \%$ & $0.15 \%$ & $0.18 \%$ & $0.53 \%$ & $0.00 \%$ \\
\hline Apoyo a Refugiados & $0.00 \%$ & $0.00 \%$ & $0.00 \%$ & $0.00 \%$ & $0.00 \%$ \\
\hline \multirow[t]{2}{*}{ No Especificado } & $0.37 \%$ & $0.26 \%$ & $0.13 \%$ & $1.08 \%$ & $1.77 \%$ \\
\hline & $100.00 \%$ & $100.00 \%$ & $100.00 \%$ & $100.00 \%$ & $100.00 \%$ \\
\hline
\end{tabular}

Fuente: Elaboración de los autores a partir de los datos de AidData 2.1. 
Cuadro A.2. Propósito de la ayuda: Nicaragua

\begin{tabular}{|c|c|c|c|c|c|}
\hline & 1990 & 1995 & 2000 & 2005 & 2010 \\
\hline Educación & $2.10 \%$ & $5.37 \%$ & $7.79 \%$ & $5.59 \%$ & $9.34 \%$ \\
\hline Salud & $2.58 \%$ & $2.48 \%$ & $4.58 \%$ & $10.11 \%$ & $9.52 \%$ \\
\hline Política Demográfica & $0.62 \%$ & $0.42 \%$ & $1.16 \%$ & $1.63 \%$ & $2.25 \%$ \\
\hline Agua Potable y Saneamiento & $1.00 \%$ & $10.11 \%$ & $8.30 \%$ & $1.26 \%$ & $3.54 \%$ \\
\hline Gobernabilidad y Sociedad Civil & $0.77 \%$ & $6.66 \%$ & $14.45 \%$ & $6.69 \%$ & $13.72 \%$ \\
\hline Otras Infraestructuras Sociales & $5.86 \%$ & $3.56 \%$ & $3.97 \%$ & $8.33 \%$ & $2.53 \%$ \\
\hline Transporte y Almacenamiento & $3.76 \%$ & $11.27 \%$ & $6.84 \%$ & $0.81 \%$ & $13.98 \%$ \\
\hline Comunicaciones & $0.00 \%$ & $0.00 \%$ & $2.43 \%$ & $0.07 \%$ & $0.22 \%$ \\
\hline Generación de Energía Eléctrica & $5.30 \%$ & $1.37 \%$ & $1.96 \%$ & $0.01 \%$ & $13.25 \%$ \\
\hline Banca y Servicios Financieros & $0.00 \%$ & $0.38 \%$ & $0.59 \%$ & $0.54 \%$ & $0.07 \%$ \\
\hline Servicios Empresariales & $0.03 \%$ & $0.00 \%$ & $0.00 \%$ & $1.70 \%$ & $1.54 \%$ \\
\hline Agricultura, Silvicultura y Pesca & $8.31 \%$ & $4.53 \%$ & $9.37 \%$ & $8.14 \%$ & $11.06 \%$ \\
\hline Industria, Minería y Construcción & $9.81 \%$ & $2.79 \%$ & $0.21 \%$ & $1.99 \%$ & $1.83 \%$ \\
\hline Política y Regulación Comercial & $0.02 \%$ & $0.01 \%$ & $0.24 \%$ & $1.24 \%$ & $1.04 \%$ \\
\hline Protección del Medio Ambiente & $0.00 \%$ & $0.27 \%$ & $0.99 \%$ & $4.73 \%$ & $2.08 \%$ \\
\hline Política de Género & $0.00 \%$ & $0.10 \%$ & $0.10 \%$ & $0.05 \%$ & $0.00 \%$ \\
\hline Ayuda Multisectorial & $6.08 \%$ & $1.06 \%$ & $1.69 \%$ & $8.21 \%$ & $1.83 \%$ \\
\hline Desarrollo Urbano & $0.00 \%$ & $0.00 \%$ & $1.33 \%$ & $0.14 \%$ & $1.98 \%$ \\
\hline Desarrollo Rural & $5.20 \%$ & $2.67 \%$ & $2.76 \%$ & $0.73 \%$ & $2.25 \%$ \\
\hline Otras Ayuda Multisectoriales & $0.00 \%$ & $0.22 \%$ & $0.57 \%$ & $0.06 \%$ & $1.36 \%$ \\
\hline Apoyo Presupuestario & $36.46 \%$ & $3.78 \%$ & $14.36 \%$ & $7.05 \%$ & $0.00 \%$ \\
\hline Seguridad Alimentaria & $1.20 \%$ & $0.22 \%$ & $4.73 \%$ & $2.38 \%$ & $0.32 \%$ \\
\hline Asistencia de Mercancías & $2.97 \%$ & $0.34 \%$ & $0.08 \%$ & $1.98 \%$ & $0.00 \%$ \\
\hline Deuda Externa & $0.00 \%$ & $40.92 \%$ & $4.07 \%$ & $22.03 \%$ & $0.00 \%$ \\
\hline Ayuda Humanitaria General & $0.00 \%$ & $0.00 \%$ & $0.00 \%$ & $0.00 \%$ & $0.01 \%$ \\
\hline Emergencia & $6.92 \%$ & $1.33 \%$ & $3.60 \%$ & $0.59 \%$ & $1.71 \%$ \\
\hline Alivio para Reconstrucción & $0.00 \%$ & $0.00 \%$ & $3.01 \%$ & $0.00 \%$ & $0.02 \%$ \\
\hline Mitigación de Desastres & $0.00 \%$ & $0.00 \%$ & $0.22 \%$ & $0.14 \%$ & $1.41 \%$ \\
\hline Costos Administrativos & $0.00 \%$ & $0.00 \%$ & $0.21 \%$ & $0.14 \%$ & $1.13 \%$ \\
\hline Apoyo a ONG & $0.00 \%$ & $0.06 \%$ & $0.07 \%$ & $0.76 \%$ & $0.00 \%$ \\
\hline Apoyo a Refugiados & $0.00 \%$ & $0.00 \%$ & $0.00 \%$ & $0.00 \%$ & $0.00 \%$ \\
\hline \multirow[t]{2}{*}{ No Especificado } & $0.99 \%$ & $0.10 \%$ & $0.33 \%$ & $2.89 \%$ & $2.01 \%$ \\
\hline & $100.00 \%$ & $100.00 \%$ & $100.00 \%$ & $100.00 \%$ & $100.00 \%$ \\
\hline
\end{tabular}

Fuente: Elaboración de los autores a partir de los datos de AidData 2.1. 